\title{
Computadores e Educação: Momentos iniciais desta relação no Brasil
}

\author{
Cristina de Melo Valente ${ }^{1}$
}
${ }^{1}$ Programa de Pós-Graduação em História das Ciências e das Técnicas e Epistemologia Universidade Federal do Rio de Janeiro (UFRJ) e Financiadora de Estudos e Projetos (FINEP)
cmvalentedterra.com.br

\begin{abstract}
This paper presents through a sociotechnical approach some events related to the beginnings of the history of computers in Brazilian public education, connecting the efforts of developing a national computer industry, its needs in terms of qualified human resources, and educational technology experiments. In this path throughout the 1970's and 1980's, associating the interests of different actors, the Brazilian informatics policy and the first project of application of informatics in education, the EDUCOM (Education with Computers) were constructed.
\end{abstract}

Resumo. Este artigo objetiva apresentar através de uma abordagem sociotécnicas alguns eventos relacionados ao início da história de uso de computadores na educação pública brasileira, conectando os esforços para o desenvolvimento de uma indústria de informática nacional, suas necessidades de formação de recursos humanos qualificados e experiências de tecnologia educacional. Nesse caminho ao longo das décadas de 1970 e 1980, associando os interesses de distintos atores, a política brasileira de informática e o primeiro projeto de uso de informática na educação, o EDUCOM (Educação com Computadores) foram construídos.

\section{Apresentação}

Este artigo buscou construir uma narrativa, baseada em pesquisa bibliográfica, cujo enredo dirigiu-se aos eventos que se encontram no começo da interseção entre informática e educação no Brasil. O percurso dessa narrativa passa pela associação da educação à formação de mão-de-obra, quando nas décadas de 1960 e 1970, o tecnicismo tornou-se "a prática oficial para utilizar os recursos audiovisuais e solucionar os problemas da educação, ... a padronização do ensino era o reflexo da produção industrial em larga escala" [TERUYA \& MORAES, 2009, p. 6].

Tal padronização, voltada à produção de mão-de-obra que o projeto de desenvolvimento e industrialização dos governos militares necessitaria, teve relação direta com as iniciativas de aplicação de diferentes tecnologias educacionais, como aquelas que utilizaram rádio, televisão e, por fim, os computadores.

O modelo de associação entre ciência e desenvolvimento, traduzido nos diferentes planos governamentais desse período, e questões de soberania, autonomia e de ausência de mão-de-obra especializada, representadas na política de informática, a partir da segunda metade da década de 1970, tiveram papel relevante na história das primeiras propostas de uso de informática na educação. 
Nessa história, em que o desenvolvimento e a utilização da tecnologia são consequências de "interações complexas entre ciência e sociedade, através das quais se torna possível mostrar que a mudança tecnológica resulta também de escolhas políticas e culturais significativas" [CUKIERMAN, 2013, p. 1], propõe-se que foram os atores da área da informática, como a Secretaria Especial de Informática (SEI), mais que os atores da área da educação, como o Ministério da Educação (MEC), que tiveram protagonismo na construção das primeiras experiências de uso da tecnologia na educação fundamental e, eventualmente, no estabelecimento de um mercado para os próprios computadores nas escolas.

\section{Introdução - Tecnologia, educação, mão-de-obra}

Em fins de 1961, quando João Goulart (Jango) assumiu a presidência do Brasil, o sistema educacional possuía altas taxas de evasão, como informa Helena Bomeny (2004, s.p.) "menos de $15 \%$ da população estudantil do ensino primário passava para o ensino médio; quase $2 \%$ da rede primária chegavam ao ensino superior e apenas $0,5 \%$ à pós-graduação", além disso, cerca de $40 \%$ da população brasileira não sabia ler e escrever. Estas situações indicaram o caminho para a agenda do governo de Jango na educação: escola pública, alfabetização de adultos e criação de vagas para os 'excedentes', aqueles estudantes que aprovados nos vestibulares não conseguiam ser aproveitados nas universidades por falta de vagas.

Para tentar enfrentar essas questões, o governo de Jango (1961-1964) formulou o Plano Trienal de Desenvolvimento Econômico e Social (1963-1965), que, alimentado pelo Plano Trienal de Educação elaborado por Darcy Ribeiro, tinha como prioridades "a necessidade de expansão do ensino primário, o desenvolvimento da pesquisa científica e tecnológica e a formação e treinamento do pessoal técnico." [GHIRALDELLI JR., 2001, p. 96].

Também fazia parte do programa de governo de Jango um conjunto de reformas, as 'reformas de base', que incluíam as reformas bancária, fiscal, urbana, administrativa, agrária e universitária. A reforma universitária de Jango propunha discutir temas como a defesa da autonomia universitária e da liberdade docente no exercício do magistério, bem como a abolição da vitaliciedade da cátedra.

No entanto, o Plano Nacional de Educação foi extinto duas semanas após o golpe militar que depôs João Goulart em 1964. Quanto à reforma universitária,

$[\mathrm{O}] \mathrm{s}$ governos militares assumiram a bandeira dessa reforma, limitando-a, contudo, a medidas de modernização administrativa e pedagógica. $\mathrm{O}$ problema dos excedentes persistiu e a estratégia adotada para enfrentá-lo, ao longo da década de 1970, teria como base a liberalização nas autorizações para a abertura de instituições de ensino superior privadas no país. [HEYMANN, 2004, s. p.]

Com a extinção do Plano Nacional de Educação, além de alterações profundas no projeto de reforma da universidade, foram inviabilizados também o Plano Nacional de Alfabetização e os núcleos de educação popular [RIBEIRO, 1993 ${ }^{1}$ apud

\footnotetext{
1 RIBEIRO, Maria Luísa Santos. História da educação brasileira: a organização escolar. Campinas, Autores Associados, 1993.
} 
PELEGRINI; AZEVEDO, 2006] e foi adotada pelo governo uma vertente economicista para a educação.

Essa vertente foi fortalecida pela teoria do capital humano que relacionava a qualificação dos recursos humanos a ganhos de produtividade e ao crescimento das taxas de lucro do capital.

Aplicada ao campo educacional, a ideia de capital humano gerou toda uma concepção tecnicista sobre o ensino e sobre a organização da educação, o que acabou por mistificar seus reais objetivos. Sob a predominância desta visão tecnicista, passou-se a disseminar a ideia de que a educação é o pressuposto do desenvolvimento econômico, bem como do desenvolvimento do indivíduo, que, ao educar-se, estaria "valorizando" a si próprio, na mesma lógica em que se valoriza o capital. O capital humano, portanto, deslocou para o âmbito individual os problemas da inserção social, do emprego e do desempenho profissional e fez da educação um "valor econômico", numa equação perversa que equipara capital e trabalho como se fossem ambos igualmente meros "fatores de produção" (das teorias econômicas neoclássicas). Além disso, legitima a ideia de que os investimentos em educação sejam determinados pelos critérios do investimento capitalista, uma vez que a educação é o fator econômico considerado essencial para o desenvolvimento. [MINTO, (2006?)]

Essa teoria embasou os acordos MEC-USAID, um conjunto de acordos de assistência técnica e financeira iniciados nos anos 1960 (até 1976) entre o MEC e a USAID (United States Agency for International Development) influenciaram as estratégias adotadas na política educacional, especialmente para o ensino superior: "a racionalização do ensino, a prioridade na formação técnica, o desprezo às Ciências Sociais e Humanas, a inspiração no modelo empresarial e o estabelecimento de um vínculo estreito entre formação acadêmica e produção industrial". [ROMANELLI, $1987^{2}$ apud PELEGRINI; AZEVEDO, 2006].

Essas influências também se fizeram sentir nas duas reformas educacionais propostas durante a vigência da Constituição de 1967, no período mais violento da ditadura: a reforma universitária (Lei ${ }^{\circ} 5.540$, de 28/11/1968) e a reforma do ensino de $1^{\circ}$ e $2^{\circ}$ graus (ensino básico), criando o ensino profissionalizante (qualificação para o trabalho). Seus objetivos já incorporavam a associação entre educação e o binômio economia/emprego:

A reforma universitária tem por objetivo oferecer resposta às demandas crescentes por ensino superior. Busca, ao mesmo tempo, formar quadros deste nível de modo a dar substância ao crescimento econômico gerado pelo "milagre brasileiro". A reforma do ensino de $1^{\circ}$ e $2^{\circ}$ graus, por sua vez, pretende atingir um duplo objetivo: de um lado, conter a crescente demanda sobre o ensino superior; de outro, promover a profissionalização de nível médio. [VIEIRA, 2007, p. 302, grifos nossos]

Para o governo militar a pedagogia tecnicista, surge como solução "para a baixa produtividade do sistema escolar (altos índices de evasão e repetência) que atrapalhava o "desenvolvimento econômico com segurança", [KUENZER E MACHADO, 1982, p.

\footnotetext{
${ }^{2}$ ROMANELLI, Otaíza. História da Educação no Brasil. Rio de Janeiro, Vozes, 1978.
} 
$30^{3}$ apud MIRA e ROMANOWSKI, 2009, p. 10209]. Naquele contexto, a tecnologia educacional era um dos instrumentos que possibilitaria transportar o modelo organizacional do sistema empresarial (baseado na "racionalidade, eficiência e produtividade") para o ensino.

Oliveira (1997) relacionou de forma direta o uso de tecnologia na educação no final dos anos 1960 ao emprego da racionalidade econômica na educação, "de forma a permitir a formação da mão-de-obra que passava a ser exigida pelo crescimento econômico e pelo processo de industrialização pelo qual passava o Brasil.” (p. 9).

Uma das estratégias adotadas para incorporar um contingente de jovens adultos a esse processo de formação de mão-de-obra foi a regulamentação do ensino supletivo pela Lei de Diretrizes e Bases (LDB) de 1971, que possibilitou também que a educação a distância se tornasse uma modalidade do ensino supletivo "mediante a utilização de rádios, televisão, correspondência e outros meios de comunicação que permitam alcançar o maior número de alunos." [BRASIL, 1971]

São exemplos marcantes do uso de tecnologia na educação deste período o Projeto Minerva do MEC (1970-1990), composto por programas radiofônicos para educação supletiva de adultos, e o Projeto SACI (Satélite Avançado de Comunicações Interdisciplinares, 1974-1978), desenvolvido pelo Instituto Nacional de Pesquisas Espaciais (INPE) para educação primária, que propunha a construção e uso de um satélite de telecomunicações para a transmissão de programação educacional. O projeto de desenvolvimento e lançamento do satélite não pode ser realizado, no entanto entre março e maio de 1975, o satélite norte-americano ATS-6 foi utilizado no programa ${ }^{4}$.

O Projeto SACI utilizou o formato de telenovelas em seu projeto piloto (e único) no Rio Grande do Norte. Foi modelado, segundo Menezes e Santos (2001), em relatório sobre a aplicação de satélite educacional nos países em desenvolvimento da universidade de Stanford (ASCEND - Advanced System for Communications and Education in National Development, $1967^{5}$ ), da qual teve consultoria. O custo de manutenção dos satélites e a distância cultural entre as produções realizadas em São Paulo e a vida dos alunos no Rio Grande do Norte foram apontados como causas para a interrupção do projeto.

O projeto SACI, envolvendo alta tecnologia de satélites e tevê para a educação básica do Rio Grande do Norte, mostrou ser um projeto elaborado de fora da própria sociedade potiguar que perdeu nele suas características de autonomia e capacidade criadora de si. Os objetivos secundários do projeto, como o desenvolvimento de uma tecnologia de satélite e tevê tornam-se, ao final, mais consistentes e importantes que $o$ ato de educar que deveria estar sendo veiculado... [ALMEIDA, 1988, p. 50]

\footnotetext{
${ }^{3}$ KUENZER, A. Z.; MACHADO, L. R. S. A pedagogia tecnicista. In: MELLO, G. N. (org.) Escola nova, tecnicismo e educação compensatória. São Paulo: Loyola, 1982, p. 29-52.

${ }^{4}<$ http://www.inpe.br/50anos/linha_tempo/68.html>, em 28 out. 2016.

Mais informações sobre o projeto SACI podem ser encontradas no repositório digital do Jornal Espacial do INPE (http://md-m09.sid.inpe.br/col/sid.inpe.br/md-m09/2011/04.06.15.25/doc/@tclPage.htm). O projeto foi tema da capa do $\mathrm{n}^{\circ} 1$ do jornal, publicado em abril de 1972.

${ }_{5}^{5}$ <https://searchworks.stanford.edu/view/849169>. Acesso em: 10 fev. 2016.
} 
Também nesse período, a associação entre ciência e desenvolvimento passou a ter destaque nos planos de ação dos governos militares, como o I Plano Nacional de Desenvolvimento (I PND - 1972-1974), que adotou como estratégia o fortalecimento da competitividade da indústria nacional em setores estratégicos, "em especial em indústrias de alta intensidade tecnológica" [DIAS, 2012, p. 100] e o I Plano Básico de Desenvolvimento Científico e Tecnológico (I PBDCT - 1973-1974), atrelado e aderente ao PND. Contando com financiamento expressivo do Fundo Nacional de Desenvolvimento Científico e Tecnológico (FNDCT), teve, entre outros, o objetivo de ampliar a capacidade de pesquisa em indústrias identificadas como prioritárias, dentre elas a 'indústria de computadores' [SALLES FILHO, 2002, p. 412].

A estratégia de fortalecimento da base tecnológica da indústria nacional, incluindo aí o "desenvolvimento de uma indústria eletrônica digital" [DANTAS, 1988, p. 51], também foi adotada no governo seguinte (1975-1979) no II PND e no II PBDCT, que reconheceu então, de forma explícita, as possíveis implicações da adoção de tecnologias 'modernas' nos 'problemas do emprego', estabelecendo relação entre a avaliação da aplicabilidade de programas de tecnologia educacional no país e as questões de valorização de recursos humanos e distribuição de renda:

Quanto à opção de melhorar a distribuição de renda e aumentar os padrões de vida da população, além dos aspectos associados à política de emprego, são ainda significativas as implicações de natureza científica e tecnológica da diretriz de valorizar os recursos humanos e compensar a má distribuição de renda através de investimentos em educação, saúde e assistência médica, saneamento e nutrição. Com este propósito, será requerido: ...o empreendimento de programas de tecnologia educacional tendentes a identificar métodos avançados de comunicação e ensino e ajuizar da sua aplicabilidade no Brasil. [SALLES FILHO, 2003(a), p. 193]

Na proposta apresentada pelo III PBDCT (1980-1985), a educação, em conjunto com a cultura, ganhou espaço próprio no texto, que, no entanto, não detalhava propostas, expondo diretrizes genéricas, assim como no resto do plano (Salles Filho, 2003(b)). A questão da capacitação de recursos humanos para a ciência foi articulada no texto à formação de recursos humanos em geral, abrigando a expectativa de que mais pessoas completassem o ciclo de formação científica e que houvesse uma "progressiva incorporação dos conhecimentos científicos à vida econômica do país." [SALLES FILHO, 2003(b), p. 417]

No período da ditadura, os processos de industrialização e urbanização do país, associados à ideia de superação do subdesenvolvimento, continuaram a avançar. Com uma política de estímulo ao crédito e ao consumo da classe média, após vários anos de recessão e desemprego, as indústrias nacionais, aproveitando a oferta de mão-de-obra barata e os recursos disponibilizados pelo governo, conseguem aumentar seus mercados e produtividade e o país, a partir do começo de 1970, vive o milagre econômico brasileiro.

Nesse período, ações na interface entre educação e tecnologia encontraram um espaço restrito nas políticas públicas. Nesta relação educação e tecnologia, a ênfase vai para a aplicação da tecnologia na educação à distância. No II PND (1975-1979), ainda dentro de política científica e tecnológica, a proposta era: 
[M]anter-se em dia com os progressos na tecnologia educacional (pelo uso de sistemas de computação e outros avanços desse tipo), além de testar a viabilidade de aplicação, no Brasil, das mais avançadas técnicas de telecomunicações na transmissão de programas educacionais a grandes massas. [BRASIL, 1974, p. 137, grifos nossos].

Alinhado ao II PND, o II PBDCT propõe o "empreendimento de programas de tecnologia educacional tendentes a identificar métodos avançados de comunicação e ensino e ajuizar da sua aplicabilidade no Brasil" [SALLES FILHO, 2003(a), p. 193]. No III PND (1980/1985), o assunto não chega a ser mencionado.

No espaço de planejamento governamental sob a responsabilidade da Secretaria Geral do MEC, as propostas apresentadas nos três Planos Setoriais de Educação e Cultura (PSEC) ${ }^{6}$ refletiram preocupações com a expansão da oferta, os padrões de desempenho e a produtividade do ensino. Nesses documentos, o desenvolvimento, experimentação de tecnologias educacionais são identificados com expectativas sobre o efeito multiplicador da teleducação e seu potencial de "atingir as massas" [MEC, 1973, p. 14], "atendendo a todos, em todos os momentos" [MEC, 1980, p. 23]. Neste diapasão, são citados no I PSEC os já mencionados projetos Minerva e SACI, a construção de um centro de produção da Fundação Centro Brasileiro de TV Educativa do MEC (FCBTVE) e a TV Educativa na Guanabara, que inicia sua operação em 1975.

Ao longo dos governos militares, o espírito desenvolvimentista das políticas de Juscelino Kubitschek foi mantido, no entanto os rumos da industrialização foram alterados em virtude da busca de autonomia da indústria nacional, motivando a implantação de diferentes políticas voltadas ao desenvolvimento tecnológico [Loureiro, 2015]. Questões como a ausência de infraestrutura tecnológica e de recursos humanos especializados foram consideradas fundamentais para o enfrentamento da dependência tecnológica e para a produção local dos bens que eram importados. Neste esforço alguns campos do conhecimento seriam priorizados no projeto de desenvolvimento econômico nacionalista. Um desses campos seria justamente a informática.

Para Dias (2012), o discurso da autonomia tecnológica como estratégia indispensável ao desenvolvimento legitimou as políticas científicas e tecnológicas defendidas durante o período da ditadura e seus planos. Da mesma forma, foi peça chave na coalizão e engajamento de pesquisadores, militares e burocratas para a construção da política de informática e da reserva de mercado para computadores (1977-1991).

Naquele momento, com os desenvolvimentos que estavam acontecendo na indústria internacional de computadores, os recursos disponibilizados pelo milagre econômico, a redução do custo dos circuitos integrados e a possibilidade de licenciar tecnologias tornou-se possível a proposição de um caminho que distanciasse a indústria brasileira do mercado dominado pelos grandes fabricantes.

Nesse caminho, enredando os interesses de distintos atores neste campo, ao longo das décadas de 1970 e 1980 foram construídas, estabilizadas e desestabilizadas, a política de informática e a reserva de mercado para minicomputadores produzidos no país com tecnologia local, especialmente a partir das alianças que levaram à

\footnotetext{
${ }^{6}$ Publicados em 1973, 1976 e 1980, para os períodos 1972-74, 1975-79 e 1980-85, respectivamente.
} 
constituição da CAPRE e posteriormente da SEI. Um entrelaçamento desta história ${ }^{7}$ com aquela das várias iniciativas de aplicação informática na educação pode ser retraçado às primeiras experiências sobre o uso de computadores na educação ainda no final da década de 60.

\section{Experimentos de uso de computadores na educação}

Valente (1999) relata que esses experimentos surgem do interesse de educadores de algumas universidades pelo que já vinha acontecendo nos EUA e na França. Ao longo dos anos iniciais da década de 1970, vários eventos foram realizados trazendo especialistas internacionais para debater o tema e demonstrar aplicações. Um exemplo muito citado é a vinda, em 1971, de Elisha R. Huggins, do departamento de Física e Astronomia do Dartmouth College, EUA, que participou de seminário sobre o uso do computador no ensino da física na Universidade Federal de São Carlos (UFSCar), realizado com o apoio do $\mathrm{CNPq}$.

No mesmo ano, foi organizada a I Conferência Nacional de Tecnologia em Educação Aplicada ao Ensino Superior (I CONTECE), que teve grande impacto na criação de novos grupos interessados no uso das tecnologias disponíveis na educação. Realizada no Rio de Janeiro, com a coordenação técnica da UFSCar. Nesta conferência, "(pela primeira vez no Brasil), um grupo da USP, liderado pelo prof. Helio Guerra Vieira..., pôs em funcionamento um terminal, no Rio de Janeiro (Hotel Glória), acoplado por um modem nacional, por telefone, a um computador localizado no campus da universidade em São Paulo.” [SOUZA, 1983, p. 2]

Em 1973, a Universidade Federal do Rio Grande do Sul (UFRGS) utilizou um computador para a simulação de fenômenos físicos em curso de graduação e a equipe de seu Centro de Processamento de Dados desenvolveu para o Burroughs B6700, adquirido em 1972, um software para avaliação de alunos da pós-graduação em educação, o SisCAI (Sistema Computer Aided Instruction). Além disso, neste mesmo ano, a UFRGS criou o Laboratório de Estudos Cognitivos (LEC), coordenado por António Battro, discípulo de Piaget, voltado para pesquisas sobre dificuldades de aprendizagem de crianças, o desenvolvimento de informática educativa, e o trabalho com crianças especiais. (Tavares, 2002)

Andrade e Lima ${ }^{8}$ (1993 apud ALMEIDA, 1999), afirmam que a Universidade Federal do Rio de Janeiro (UFRJ), através de seu Núcleo de Tecnologia Educacional para a Saúde (Nutes), foi a primeira universidade a empregar a informática na educação, quando, também em 1973, utilizou simulações por computador para o ensino de Química na área de Saúde e Administração Hospitalar. Para Oliveira (1980), este projeto foi um bom exemplo de como a tecnologia poderia ser uma estratégia para inovação na educação, na qual o componente tecnológico não é o principal fator, mas

\footnotetext{
${ }^{7}$ Existe uma farta literatura documentando e analisando a política nacional de informática. Aspectos da história da construção desta política podem ser encontrados em: MARQUES (1980, 2000, 2003, 2010, 2012 e 2014); HELENA (1980, 1984); MACEDO (1982); ADLER (1986); DANTAS, V. (1988); DANTAS, M. (1989); FAJNZYLBER (1994); MOREIRA (1995); MORAES (1996); SOARES (2002); GARCIA \& ROSELINO (2004); GUTIERREZ (2010); SALLES FILHO et al (2012); CUKIERMAN (2012 e 2014) e VIANNA (2014, 2015a e 2015b), entre outros.

8 ANDRADE, Pedro Ferreira de; LIMA, Maria Candida Moraes de Albuquerque. Projeto Educom. Brasília, MEC-OEA, 1993.
} 
um 'catalítico crítico', sem o qual as reformas no ensino pretendidas não teriam sido possíveis.

Nesse mesmo período, segundo relato de Chaves (1983), iniciou-se o projeto Logo na Universidade Estadual de Campinas (Unicamp) a partir de um estágio de Afira Vianna Ripper no laboratório $\log _{0}^{9}$ do Massachusetts Institute of Technology (MIT), em 1973 e 1974, onde conheceu Seymour Papert e Marvin Minsky, pesquisadores do MIT que desenvolviam trabalhos sobre o uso de computadores na educação de crianças. Estes professores foram convidados a visitar a Unicamp em 1975, e, como resultado desta visita, formou-se um grupo interdisciplinar de pesquisa. No ano seguinte, Papert e Minsky retornaram à Unicamp e pesquisadores do grupo estagiaram no MIT, entre eles, José Armando Valente que faria seu doutorado no laboratório Logo, sob a orientação de Papert. Em 1978 o grupo de pesquisa passou a desenvolver atividades com crianças e o Núcleo Interdisciplinar de Informática Aplicada à Educação (NIED) foi criado em 1983, tendo como atividade central o Projeto Logo.

Ainda em 1974, Valente e um aluno desenvolveram um software do tipo Instrução Auxiliada por Computador (Computer Aided Instruction - CAI) para o ensino da linguagem de programação BASIC que foi utilizado por alunos do mestrado em ensino de ciências e matemática. Ainda de acordo com Valente (1999), em 1976, professores do Departamento de Computação elaboraram um documento chamado "Introdução a Computadores. Versão Experimental"10, voltado para as escolas de $2^{\circ}$ grau.

A produção desse texto foi financiada pelo Programa de Expansão e Melhoria do Ensino (PREMEN/MEC) [Valente, 1999]. Este programa, criado na década de 1960 e orientado para a profissionalização de jovens, a partir da LDB de 1971, viria a ser um dos instrumentos da expansão do modelo de ensino profissionalizante.

O NUTES (UFRJ), o LEC (UFRGS) e o NIED (UNICAMP) viriam a coordenar, dez anos depois, projetos de pesquisa de suas respectivas universidades dentro do projeto Educação com Computadores (EDUCOM), um esforço concentrado de pesquisa sobre a aplicação de computadores ao ensino, realizado através de experimentos liderados por universidades e que foi considerado por Oliveira (1993) como "o primeiro projeto governamental brasileiro de Informática na Educação.” (p. 91).

\section{CAPRE, SEI e Educação}

Enquanto estas experimentações aconteciam nos grupos de pesquisa educacional nas universidades, na primeira metade da década de 1970, foram organizados os Seminários de Computação na Universidade (SECOMU) nos quais eram compartilhadas experiências de pesquisa e debatidos conteúdos de cursos e currículos de informática. Estes seminários, em especial o de 1974, em Ouro Preto, organizado com a ajuda da CAPRE, também foram espaços onde se aproximaram os articuladores da construção da

\footnotetext{
${ }^{9}$ Linguagem de programação para crianças desenvolvida no final da década de 1960. Para maiores informações, ver: CHAKRABORTY Anit; GRAEBNER Randy; STOCKY, Tom. LOGO: A Project History, MIT, dec. 1999, 40 p. [The Structure of Engineering Revolutions, Final paper]. Disponível em: <http://web.mit.edu/6.933/www/LogoFinalPaper.pdf>. Acesso em: 13 abr. 2015.

10 Takahashi, E.T, Valente, J.A, Bianchini, S.M., Ferrari, J.O. \& Vanini, F.A. (1976). Introdução a Computadores. Versão Experimental, Campinas: IMECC-UNICAMP.
} 
política de informática e a comunidade acadêmica de informática, "uma importante aliada, não só para a definição dos rumos [da política] como, também, para ajudar na caminhada". [DANTAS, 1988, p. 55]

Alinhavando argumentos como a autonomia tecnológica, a balança comercial ${ }^{11} \mathrm{e}$ a segurança nacional, uma comunidade formada por acadêmicos (especialmente, em informática), empresários, militares e burocratas estatais, que para Marques (2000) configurou "um coletivo técnica e politicamente agenciador". (p. 99), a CAPRE teve um papel pioneiro no engajamento de diversos interesses no tema educação (para a operação e a produção de computadores), engajamento que iria, após a desestabilização da CAPRE e o surgimento da Secretaria Especial de Informática (SEI), ao encontro das competências construídas ao longo da década de 1970 nos grupos de pesquisa universitários (principalmente, nas áreas de educação e na psicologia).

No enredo aqui desenvolvido, o fato de que, dentre as recomendações que levaram à criação da própria CAPRE, estivesse o "estabelecimento de um plano de treinamento intensivo, em todos os níveis, das técnicas computacionais". [DANTAS, 1988, p. 40] foi considerado representativo da relevância assumida pela questão de formação de recursos humanos qualificados para a indústria de informática naquele momento. Da mesma forma, o anúncio antecipado da criação da CAPRE (oficialmente criada em abril de 1972), feito pelo próprio ministro do Planejamento João Paulo dos Reis Veloso, ainda em meados de dezembro de 1971, no Rio de Janeiro [Dantas, 1988, p. 41] durante um Simpósio Internacional de Ensino em Computação, também parece apontar para a importância do tema e da comunidade que dele tratava.

As recomendações mencionadas constaram de um estudo intitulado "Esboço de Plano Nacional de Computação Eletrônica", que havia sido encomendado pelo secretário geral do Ministério do Planejamento e Coordenação Geral, Henrique Flanzer, e organizado por Antonio Cesar Olinto de Oliveira, diretor fundador do Instituto Brasileiro de Informática do IBGE (IBI/IBGE). O estudo seria entregue em 8 de dezembro de 1971, poucos dias antes do anúncio da criação da CAPRE pelo ministro do planejamento [Dantas, 1988, p. 40].

Assim, em 5 de abril de 1972, quando por meio do Decreto $\mathrm{n}^{\circ} 70.370$ é formalmente criada a CAPRE, esta já contava entre suas atribuições a coordenação de "programas de treinamento em todos os níveis de técnicas computacionais, fazendo uso dos programas já existentes nas universidades, escolas e centros de pesquisa" [BRASIL, 1972].

Vinculam-se assim, questões relativas à 'preparação de recursos humanos' com capacidade de operar, manter e desenvolver equipamentos para o processamento eletrônico de dados no Brasil às finalidades da Comissão ("adotar e propor medidas visando à racionalização dos investimentos governamentais no setor e à elevação da produtividade na utilização dos equipamentos de processamento de dados instalados e a instalar" [BRASIL, 1972] e as discussões e esforços de uma tecnocracia idealista [DANTAS, 1988, p. 7], que contribuirá na CAPRE para a criação da Política Nacional de Informática.

\footnotetext{
${ }^{11}$ Em 1974, o déficit comercial no setor eletro-eletrônico chegou a mais de US\$ 600 milhões e quase 99\% do mercado nacional foram atendidos por importações. [DANTAS, 1988, p. 59]
} 
O tom de urgência e preocupação com a formação de recursos humanos pode ser percebido em matéria publicada na coluna do jornalista Joelmir Beting no jornal Folha de São Paulo, em outubro de 1972, que registrou a participação do ministro Reis Veloso no V Congresso Nacional de Processamento de Dados, em Brasília. Ao comentar a escassez crônica de profissionais especializados, o ministro afirmava que o Brasil corria "o risco de ter mais computadores que manejadores dessas máquinas que trabalham na estratosfera de nossa imaginação...”. Para resolver esta situação, o ministro propunha a criação de programas de treinamento, aliando os setores público e privado, quebrando o monopólio dos fabricantes de computadores e das universidades:

Em outras palavras: o titular do Planejamento propõe um esquema capaz de casar teoria com pratica, fornecedor com usuário, escola com empresa. É uma corrida contra o relógio. O Brasil acaba de definir uma política de informática, voltada para a solução de problemas levantados pelo crescimento a toque de caixa da economia tupiniquim. Dois mecanismos já estão instalados: a Comissão de Coordenação das Atividades de Processamento Eletronico, junto ao Ministério do Planejamento, e o Instituto Brasileiro de Informatica, um "banco de dados" acoplado à potente engrenagem do IBGE. [BETING, 1972, p. 21]

Durante o primeiro ano de operação da CAPRE foi proposta ao seu Conselho Plenário a organização do Programa Nacional de Ensino de Computação. A proposta é articulada a partir dos resultados de um levantamento das necessidades de recursos humanos e das instituições que formavam profissionais de computação, coordenado por Luiz Martins. Integrante do grupo inicial de quatro funcionários da CAPRE (além dele, Ricadro Saur, Murilo Matos e Gilson Betame), havia trabalhado na IBM, a serviço da Pontifícia Universidade Católica do Rio de Janeiro (PUC-Rio) que havia adquirido um IBM 7044, para onde posteriormente se transferiu como responsável pelo CPD daquela universidade (RioDataCentro - RDC) onde, segundo Staa (2003), foi o criador do curso de Tecnologia em Processamento de Dados.

Coube a Martins coordenar o trabalho de reunir os elementos para propor ao Plenário as diretrizes de um Programa Nacional de Ensino de Computação. Deveria levantar a demanda de pessoal nos próximos três anos, as instituições que promoviam ensino em computação e concluir sugerindo medidas para corrigir distorções e apontar as necessidades de ensino. Martins sentiu-se à vontade nessa tarefa, pois, ao ajudar a implantar, na PUC, o programa de mestrado em informática, penetrara em uma área até então exclusiva das multinacionais: a formação de gente [DANTAS, 1988, p. 42].

Para Tigre $^{12}$ (1989 apud Moraes, 1996, p. 70) este teria sido o primeiro levantamento da situação dos recursos humanos na área de computação. No entanto, uma versão ligeiramente diferente é relatada por Castro (2011, p. 21). Nela, logo após a criação da CAPRE, o também recém-criado IBI (Instituto Brasileiro de Informática) realizou um estudo sobre a disponibilidade de recursos humanos para $\mathrm{o}$ desenvolvimento de projetos de informática que constatou "um déficit acentuado de profissionais de nível médio e superior". Para Castro esse resultado foi decisivo "para

12 TIGRE, P. B. Recursos humanos na indústria brasileira de processamento de dados. In: UNICAMP/NPCT/IG, Educação e Desenvolvimento tecnológico: o caso da informatização da indústria no Brasil, Campinas, 1989. 
que a área de educação fosse mobilizada a envolver-se no processo", levando à integração do MEC ao Conselho da CAPRE em 1976.

“Assim, em 1973, a CAPRE obteve, afinal, a primeira fotografia do crescimento da informática no Brasil" [DANTAS, 1988, p. 43]. Tal fotografia mostrava que no país existiam 700 computadores em 636 instalações que empregavam 11.125 profissionais. A análise dos dados levantados apontava um déficit de profissionais, em termos de quantidade e de experiência (a maioria não tinha mais que três anos de experiência).

\begin{abstract}
O trabalho concluiu com onze recomendações, todas voltadas para o aprimoramento da formação de pessoal. Deveria ser criado um fundo para a aquisição de material didático; formar-se instrutores, inclusive com deslocamentos temporários de profissionais entre as regiões do país; incluir-se a computação nos currículos das escolas de primeiro e segundo grau etc.”. [DANTAS, 1988, p. 43, grifos nossos]
\end{abstract}

Para Moraes (1996, p. 70), o Programa Nacional de Treinamento em Computação (PNTC) foi uma das ações desenvolvidas em resposta ao resultado do levantamento. Esta autora considera que este programa poderia disputar o título de "primeiro programa nacional" de informática na educação em uma historiografia alternativa àquela que identifica como marcos iniciais dessa história os eventos que ocorreriam apenas na década de 80 , promovidos no âmbito da SEI, e que levariam à constituição do projeto EDUCOM.

Em 1976, após a reestruturação da CAPRE, o MEC, então no Conselho Plenário da Comissão, teria sido, segundo Castro (2011), decisivo na implementação do PNTC. A respeito desse programa foi possível localizar informação de um convênio assinado em 1975 entre a CAPRE e o Laboratório de Técnicas Digitais LTD/DATAMEC para a execução de projeto de treinamento no âmbito do PNTC, com recursos do Fundo de Desenvolvimento de Áreas Estratégicas (FDAE) alocados ao PNTC (DIÁRIO Oficial da União, 1975, Seção 1, p. 5590-92).

O extrato do convênio previa os itens que deveriam constar de cada projeto (Objetivos, Programa, Metodologia, Material de Suporte, etc.) e que os materiais gerados poderiam ser utilizados pela CAPRE "tanto na rede de ensino do $2^{\circ}$ grau quanto na rede universitária e em cursos de órgãos do governo e empresas públicas" (Cláusula Sexta, p. 5591).

Ainda de acordo com extrato do convênio, as Normas de Aplicação do PNTC já haviam sido publicadas no Boletim Informativo da CAPRE em sua edição de julho/setembro de 1974. Assim, embora a entrada no MEC para o Conselho Plenário da CAPRE possa ter sido decisiva para o desenvolvimento do PNTC, não o foi para sua criação, que data, pelo menos, de 1974.

Outro rastro deixado pelo PNTC pode ser encontrado no Boletim do Centro de Computação (CECOM) da UFMG, publicado em 1977, que trazia notícia sobre um curso de Técnicas de Programação, desenvolvido por aquele centro com recursos do PNTC, em Natal, Rio Grande do Norte. [O SISTEMÁTICO, 1977]. Portanto o PNTC continuou operando ao longo da década de 1970, cabendo à SEI, após a extinção da CAPRE, sua condução (CASTRO, 2011, p. 46). Em fevereiro de 1980, poucos meses após a criação da SEI, é assinado um termo aditivo a um convênio firmado em 1975 entre a Secretaria de Planejamento e a Financiadora de Estudos e Projetos (FINEP), no papel de gestora dos recursos, "a fim de dar continuidade ao Programa Nacional de 
Treinamento em Computação - PNTC ..." [CONSELHO, 1980], no qual a SEI assume os direitos e obrigações atribuídos à CAPRE antes de sua extinção.

Voltando ao início da atuação da CAPRE, em 1974, no começo do governo Geisel, um documento chamado Esboço de uma Política Nacional de Informática para o Brasil foi elaborado pela equipe daquela Comissão. Propunha estratégias para uma política industrial e de desenvolvimento tecnológico e contemplava a necessidade de formação de profissionais e de chamar a atenção da sociedade para a importância da informática para o Brasil. Naquele momento, já era clara para a CAPRE a necessidade de contar em seu plenário com representantes de outros ministérios, como o da Educação [DANTAS, 1988, p. 52-3]. Esta necessidade, como já foi mencionado, seria atendida formalmente a partir do Decreto $\mathrm{n}^{\mathbf{0}} 77.118$, que, em fevereiro de 1976, formalizou a reformulação da Comissão para que ela pudesse conduzir a Política de Informática ${ }^{13}$, e incluiu os ministérios da Educação, das Comunicações, e da Indústria e Comércio no Conselho Plenário, seu órgão deliberativo. Esta responsabilidade pela condução da política foi registrada por HELENA (1980):

Caso único entre os diversos setores da indústria, para a de computadores passou-se a depender da anuência prévia de um organismo do Estado, a CAPRE, para a importação de equipamentos, partes e peças, o que acontecia em 1975 sob a motivação imediata do controle do balanço de pagamentos. Em fevereiro de 1976 a CAPRE recebia ainda a incumbência de formular a política para o setor e, ao se delegar a ela tal função, há implícito o reconhecimento de não haver até então uma política estruturada e da necessidade da criação de uma base institucional para as decisões na área. (p. 77)

Um pouco antes disso, no ano seguinte à divulgação do esboço de uma Política Nacional de Informática, em 1975, José Carlos Lucena da PUC-Rio e Luiz Martins apresentaram uma comunicação na Conferência da International Federation for Information Processing (IFIP), chamada "A multilevel national approach to computer education" (Uma abordagem multinível à educação para a computação). No relato publicado, os autores já mencionavam o esforço conjunto de CAPRE e MEC, a experiência dos SECOMU e apresentavam um programa integrado para educação em computação, que estaria em processo de construção e implantação no Brasil.

Os autores deixaram claro que a obtenção de um nível adequado para a formação de especialistas em computação fazia parte do escopo de atuação da CAPRE, e que esta necessidade motivou a colaboração entre CAPRE e MEC [LUCENA; MARTINS, 1975, p. 146], para o desenho de um conjunto de diretrizes que orientava os esforços de planejamento da educação em computação, a criação de escolas de nível superior voltadas ao tema, a cooperação inter-regional, a realização de eventos e o treinamento de professores. $\mathrm{O}$ artigo detalhava algumas das atividades realizadas em cada uma dessas estratégias até aquele momento (p. 146-8).

Especificamente no que diz respeito à diretriz de planejamento da educação, como parte das suas atividades a CAPRE avaliava as necessidades de profissionais no país, e para tal havia definido, a partir de esforço inicial da Sociedade de Usuários de

${ }^{13}$ Dentre as competências do Conselho Plenário (art. $4^{\circ}$ ), o primeiro item tratava de deixar claro sua principal função: "propor as diretrizes da Política Nacional de Informática e o Plano Integrado de Informática” [BRASIL, 1976] 
Computadores e Equipamentos Subsidiários (SUCESU) e com a ajuda de representantes da indústria, uma descrição das demandas por profissionais de computação no Brasil. Esta descrição organizava-se para dar conta de três categorias de demandas: Sensibilização; Computação como um meio; e Computação como um fim. Um quadro ao final do texto do artigo resume os interesses e pontos de vista que os autores representavam aqueles dos 'planejadores brasileiros', a partir da distribuição dos vários tipos de 'fornecedores' de educação em computação nas três categorias mencionadas, ou seja, identificando "o programa educacional requerido por área de atividade" (p. 146).

Por exemplo, o ensino de nível secundário ${ }^{14}$ seria um 'fornecedor' para as seguintes demandas: Sensibilização do público em geral; Perfuradores de cartão e codificadores; Preparadores de dados; Operadores; e Programadores de aplicações (p. 149). É interessante notar que 'TV, Rádio, Jornais e Outros meios' são considerados fornecedores para quase todas as áreas de atividade, com exceção de: Perfuradores de cartão e codificadores; Manutenção e manufatura. Uma possível explicação para isso seria um entendimento por parte dos autores de que estas atividades específicas exigiriam uma educação exclusivamente presencial, para a qual conteúdos trazidos pelos meios de comunicação não teriam como colaborar.

Neste mesmo trabalho, foi apresentada uma figura que representava o modelo de integração das atividades educacionais de todos os níveis educacionais (primário, secundário, graduação e pós-graduação) no sistema proposto pelos autores. Esta imagem, reproduzida na Figura 1, utilizava a simbologia dos fluxogramas, com seus processos, conectores e setas, representando as conexões esperadas entre os conteúdos educacionais e as carreiras profissionais. Um fluxo sequencial em que são explicitados: uma ordem definida, os meios necessários e os produtos desejados. Tratava-se da materialização de expectativas, no tema educação para a computação, existentes no grupo dos profissionais de informática, em meados da década de 1970. Esta representação é especialmente interessante por já alinhar o ensino nos níveis primário e secundário como contribuintes na formação dos profissionais que permitiriam a um "país em desenvolvimento ser capaz de aproveitar plenamente os múltiplos usos da tecnologia da computação" [LUCENA; MARTINS, 1975, p. 148].

No modelo apresentado, o ensino primário contribuiria em termos de educação geral ao introduzir elementos da abordagem algorítmica e, em termos de educação profissional, ao discutir informação (por exemplo, os aspectos de coleta, tratamento e distribuição) e informática (por exemplo, o papel do computador em uma sociedade moderna; aplicações simples; e profissões em informática). No ensino secundário, seriam formados profissionais específicos, como codificadores, técnicos ${ }^{15} \mathrm{e}$ programadores (para o desenvolvimento de aplicações, mas não de sistemas), e evidenciada a expectativa de que aqueles estudantes que se encaminhassem ao tema 'tecnologia de sistemas digitais' poderiam continuar sua formação no nível universitário, enquanto aqueles que se encaminhassem para o 'processamento de dados', encerrariam sua formação no nível secundário.

\footnotetext{
$14 \mathrm{Na}$ tradução foi mantida a terminologia utilizada pelos autores com base nas divisões de ensino existentes na época, ou seja, ensinos primário, secundário, universitário e pós-graduação (elementary school, secondary school, undergraduate programs, graduate programs).

15 Embora o documento esclarecesse que os cursos de nível secundário para codificadores e programadores não existiam no país naquele momento. [LUCENA; MARTINS, 1975, p. 146]
} 


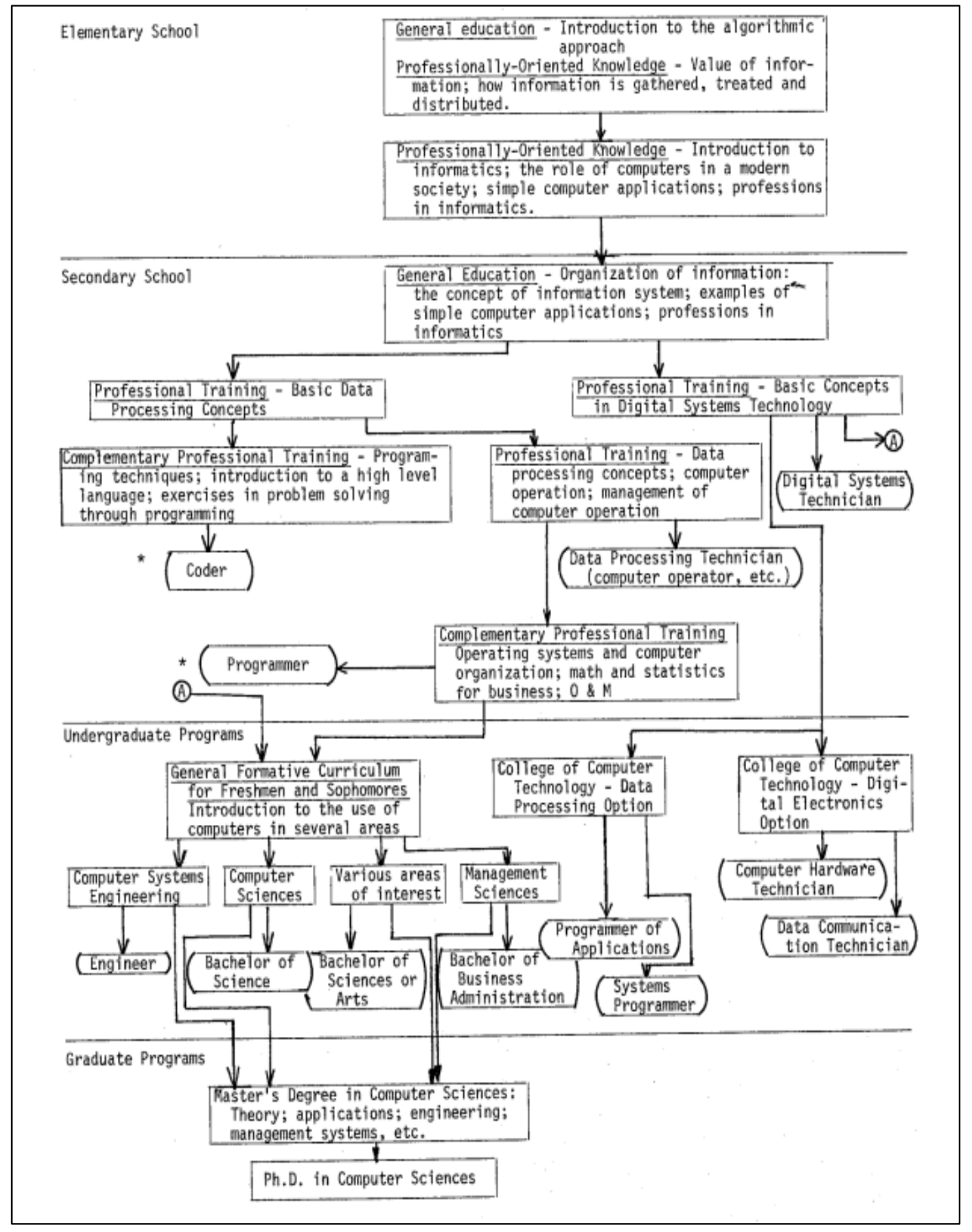

Figura 1 - Sistema integrado de educação para a computação - Proposta (1975)

Fonte: LUCENA; MARTINS, 1975, p. 150.

A partir de dados obtidos em outro levantamento sobre o setor de processamento de dados realizado pela CAPRE em 1976, que compilou informações sobre instituições, empresas, recursos humanos e a estrutura econômica da atividade, Paulo Brígido Rocha Macedo (1982), analisou a formação do mercado de trabalho para profissionais de processamento de dados no Brasil. Em uma das análises realizadas mostrou que, apesar da proporção das despesas com pessoal (mais de 50\% do total de despesas em 
processamento de dados) no Brasil ter sido semelhante à que havia sido encontrada pouco antes nos EUA, a forma como se deu a apropriação do conhecimento técnico trazido pelo computador foi muito diferente nos dois países.

Nos Estados Unidos, o desenvolvimento do computador ocorreu, com o apoio de recursos governamentais, nas instituições de pesquisa das universidades, que também formariam os futuros profissionais para as empresas, assim como os futuros usuários para as aplicações mais sofisticadas que seriam desenvolvidas.

Já no Brasil, a entrada da tecnologia aconteceu principalmente através da importação do próprio computador. Assim, o foco inicial das atividades foi $o$ desenvolvimento de aplicações que 'mecanizassem' atividades já realizadas na rotina informacional das empresas. Além disso, as empresas fornecedoras dos equipamentos assumiram a tarefa de formar os profissionais necessários para operar os computadores de seus clientes, a princípio sozinhas e depois com a participação das grandes empresas públicas brasileiras. Somente após essa fase, as universidades brasileiras iniciariam sua contribuição na formação dos profissionais necessários para o 'processamento dos dados'.

Muito embora a qualidade e a intensidade desses treinamentos pudessem ser discutidas. Dantas (1988) informa que durante a análise da CAPRE do projeto da IBM para a produção de minicomputadores no Brasil em 1977 "[U]m dos grandes argumentos da IBM em apoio às suas afirmações de estar contribuindo para o desenvolvimento nacional era o de transferir tecnologia para cerca de 400 fornecedores locais, submetidos a intenso treinamento. A CAPRE, de imediato, pediu a relação desses 400 fornecedores. A IBM só conseguiu listar 96, dos quais só com nove mantinha programa de treinamento. Dos 96, quase todos, na verdade, forneciam materiais de escritório, de transporte, de limpeza etc." (p. 78)

Antes de 1972, a capacitação de profissionais ainda dependia fortemente dos 'cursos gratuitos' ofertados pelas empresas, em 1977 quarenta cursos de graduação e pós-graduação já eram oferecidos por universidades brasileiras [SAUR, 1977, p. $17^{16}$ apud ADLER, 1986, p. 688], fortalecidas por financiamentos da Finep e do Conselho Nacional de Desenvolvimento Científico e Tecnológico $(\mathrm{CNPq})$ e pelo retorno dos pós graduados que haviam se formado em universidades estrangeiras.

No Apêndice A da dissertação de Macedo (1982), encontram-se modelos de questionários utilizados pela CAPRE em 1977 para o levantamento dos recursos computacionais brasileiros. Estes questionários, organizados em dois cadernos, que tratavam, respectivamente, da estrutura computacional e da qualificação dos profissionais ligados às atividades de processamento de dados das empresas e instituições, são registros que demonstram as preocupações da CAPRE com a situação da capacitação de recursos humanos.

No caso específico do segundo caderno, os objetivos apresentados traduziram a preocupação com o 'mercado de recursos humanos', sem o qual a política de informática em construção não poderia prosperar. O levantamento de informações sobre a formação, a experiência e os treinamentos realizados pelos profissionais das instituições usuárias de computadores no Brasil visava em última instância: "traçar um

\footnotetext{
${ }^{16}$ SAUR, Ricardo Adolfo de Campos. Hearings before the Parliament (Câmara dos Deputados, Comissão
} de Ciência e Tecnologia). Mimeo, Brasília, ago. 1977, p. 17. 
perfil profissional, o que beneficiará o mercado de recursos humanos em processamento de dados". [MACEDO, 1982, Apêndice A].

Como indícios espalhados no tempo, os questionários da CAPRE analisados por Macedo, o modelo educacional proposto por Lucena e Martins e o convênio publicado no Diário Oficial da União em 1975, resgatam a imbricação entre o início da construção da política nacional de informática, ainda durante a existência da CAPRE, e a questão da educação, do ponto de vista da formação de profissionais para a computação.

Com a ampliação de suas competências a partir de 1976, a CAPRE passou a ter uma atuação mais direta sobre a indústria instalada no Brasil, ou que começava seu desenvolvimento, através da construção de uma política de informática que se distinguiu do padrão adotado pela maior parte da indústria brasileira, voltado quase exclusivamente à substituição de importações. Na política de informática desenhada pela CAPRE, uma das prioridades foi o desenvolvimento de uma capacitação tecnológica das empresas brasileiras [FAJNZYLBER, 1994, p 252] que passava necessariamente pela formação e qualificação de profissionais.

Ao longo do período de existência da CAPRE ficaram cada vez mais associados a autonomia na indústria da informática, a soberania nacional e o sistema educacional (inicialmente de nível superior e, posteriormente, também os níveis médio e fundamental), às condições industriais. Para Marques (1980):

\begin{abstract}
Ponto fundamental a ser constantemente colocado pela e para a universidade brasileira é como poderá ela contribuir efetiva e diretamente para que o processo de incorporação de know-how nacional aos meios de produção brasileiros se desenvolva rapidamente na área de computação. Incorporar este ponto às suas funções na sociedade não só é inteiramente adequado aos grupos brasileiros de pesquisa tecnológica na área de computação, como também pode levar a atividade de pesquisa a assumir o papel de elemento natural de vinculação do ensino às nossas condições industriais. Fazendo uma pesquisa destinada especificamente a melhorar e ampliar a capacidade tecnológica da indústria brasileira, estar-se-á ligando diretamente o sistema educacional - máquina que prepara a mão-de-obra qualificada - às condições tecnológicas da nossa indústria, que é precisamente o sorvedouro do pessoal qualificado preparado em nossas instituições de ensino superior e centros de pesquisa. (p. 141)
\end{abstract}

A respeito deste ponto, Castro (2011, p. 40), ao analisar a construção da política de tecnologia educacional brasileira, afirmou que mais do que a iniciativa ou o interesse do MEC, os atores envolvidos com a formulação da política de informática foram aqueles que mobilizaram o estabelecimento da relação entre educação e tecnologia da informação. O MEC foi incluído nas discussões da CAPRE em virtude dos interesses existentes pela capacitação de recursos humanos para o setor de informática e não por demandas das escolas ou universidades. Assim, em seus momentos iniciais de construção e estabilização, as políticas nacionais de tecnologia educacional se aproximaram mais das diretrizes que impulsionaram a política de informática do que daquelas que mobilizaram a política educacional.

Com o fim do governo Geisel em março de 1979 e a escolha do general Figueiredo para a presidência do Brasil, também chegou ao fim a trajetória da CAPRE. Os rearranjos sociotécnicos desse período foram amplamente discutidos por Vera 
Dantas (1988) e por Ivan Marques (2003), que relataram o processo de construção e imposição de uma nova narrativa que levaria à criação da Secretaria Especial de Informática $(\mathrm{SEI})^{17}$, ligada diretamente à Presidência da República com status de ministério (Marques, 2000 e 2003), no âmbito do Conselho de Segurança Nacional da Presidência da República (CSN/PR).

[A] substituição da CAPRE pela SEI... não foi somente um ato administrativo mas também uma truculenta intervenção política da polícia política da ditadura - o SNI (Serviço Nacional de Informações) - que marcou um repentino afastamento da condução da Política Nacional de Informática de práticas democráticas que eram exercidas pela CAPRE em meio ao governo ditatorial. [MARQUES, 2010, p. 5]

No entanto, para Dantas (1988), a forma colegiada de deliberação exercitada pela CAPRE acabou por ser adotada também pela SEI, que criou uma Comissão de Informática, para a elaboração da Política Nacional de Informática, na qual o MEC manteve sua representação. No documento que descreve o I Plano Nacional de Informática e Educação (I PLANIN), aprovado em 1986, que tem em sua introdução uma breve contextualização da história da política de informática, esta opção é ressaltada:

\begin{abstract}
A estratégia governamental para o setor de informática consolidou-se em 1979, com a explicitação das diretrizes da Política Nacional de Informática. Para executar essa política, a Secretaria Especial de Informática, então constituída, apoiou-se nos trabalhos de comissões especiais de caráter temporário, que contavam com ampla representatividade dos diversos segmentos da sociedade. [BRASIL, 1986]
\end{abstract}

Como forma de controlar as expectativas dos vários atores, a SEI criou espaços de discussão, mas não de deliberação, as chamadas Comissões Especiais, para as quais eram convocados especialistas e representantes de setores e instituições para discutir e propor ações. Um desses setores foi a Educação. [VIANNA, 2015(a)]

Em função da necessidade de formar recursos humanos para o setor de informática, a SEI cria a Comissão Especial n. ${ }^{\circ}$ 1: Educação $(\mathrm{CEE}-1)^{18} \mathrm{em}$ março de 1980, coordenada pelo subsecretário de estudos e planejamento, contou em sua composição com representantes da comunidade de informática (Sociedade Brasileira de Computação - SBC e Sociedade de Usuários de Computadores e Equipamentos Subsidiários - SUCESU), da comunidade governamental na temática educação (Conselho Federal de Educação - CFE e Secretaria de Ensino Superior - SESU/MEC) e da comunidade acadêmica (cinco Instituições de Ensino Superior autorizadas a realizar cursos na área de Informática). De acordo com Moraes (1996 e 2011), a composição da

\footnotetext{
17 “A 9 de outubro, o Decreto 84.067/79, assinado pelo presidente Figueiredo, criou a Secretaria Especial de Informática - SEI - "como órgão complementar do Conselho de Segurança Nacional", e extinguiu a CAPRE. À SEI competiria doravante "assessorar na formulação da Política Nacional de Informática" e "coordenar sua execução... tendo em vista, especialmente, o desenvolvimento científico e tecnológico do setor". (DANTAS, 1988, p. 122)

Outros relatos dos eventos deste período de transição entre CAPRE e SEI podem ser encontrados também em HELENA (1980) e MORAES (1996).

${ }^{18}$ A CEE-1/80 foi criada através da Portaria no. 01, de 14 de março de 1980. (Diário Oficial da União, Seção I, 19 mar. 1980, p. 9-10. <http://www.jusbrasil.com.br/diarios/3181837/pg-10-secao-1-diariooficial-da-uniao-dou-de-19-03-1980/pdfView>. Acesso em: 28 out. 2016).
} 
CEE-1/1980 contou com representantes das seguintes universidades: Universidade de São Paulo (USP), Puc-Rio, Universidade Federal de Minas Gerais (UFMG), Universidade Federal de Pernambuco (UFPe), UFRGS, e Faculdade Tecnológica (Fatec).

Com o objetivo explícito de "realizar estudos sobre a aplicabilidade da informática na educação, acompanhar as pesquisas brasileiras em desenvolvimento, conhecer as experiências francesa e americana e poder, com esses subsídios, gerar normas e diretrizes para a área de informática na educação" [BONILLA, 2000], a CEE1 foi a primeira comissão especial criada pela SEI. Em 1980 foram criadas pela SEI outras quatro comissões especiais: 02- Microeletrônica; 03 - Software e Serviços; 04 Teleinformática e 05 - Controle de Processos ${ }^{19}$.

Como resultado de suas recomendações foram desenvolvidas propostas para a investigação do uso de microcomputadores em outras áreas além do projeto EDUCOM para a área de educação, como os projetos: Microcomputadores na Medicina (MICROMED), Agropecuária e Computadores (AGROCOM), e Microcomputadores na Pequena e Média Empresa (MICROPEME) (Chaves, 1988 e Sarti, 2002).

Ainda no âmbito das atividades da CEE-1, em junho de 1981, a

Secretária de Ensino Superior (SESU) do MEC faz as primeiras consultas às universidades, procurando detectar as que já possuíam projetos voltados para a aplicação de informática na educação ou que demonstravam interesse pelo assunto. Na mesma época, a SEI envia um representante ao IV Congresso Mundial de Informática na Educação, realizado em Lausane, Suíça, e em missão prospectiva à França, buscando conhecer, junto ao governo e às indústrias francesas, o que se fazia nessa área. [CHAVES, 1988]

Como estratégia para ampliar o debate, e o levantamento de informações, e envolver a comunidade acadêmica, a SEI, o CNPq e o MEC organizaram, em agosto de 1981, o I Seminário Nacional de Informática na Educação, realizado em Brasília, de 25 a 27 de agosto de 1981, para o qual foram convidados especialistas da França e da Argentina, Françoise Faure (Serviço Internacional da Direção das Indústrias Eletrônicas e de Informática do Ministério da Indústria francês) e Felix Kierbel, Diretor do Centro Nacional de Ensino de Informática do Ministério da Cultura e Educação da Argentina (RESENHA, 1983, p. 36 e VALENTE, 1999, p. 3), e representantes das universidades identificadas na consulta realizada pela SESU/MEC: Universidade de Brasília (UnB), Unicamp, USP, UFRGS, UFRJ, UFMG, Universidade Federal de Uberlândia (UFUb), Universidade Federal da Paraíba (UFPB), Pontifícia Universidade Católica do Rio Grande do Sul (PUC-RS) e PUC-Rio, Universidade Gama Filho e a Fundação Educacional do Distrito Federal.[SARTI, 2002, p. 111].

O encontro foi organizado a partir de três temáticas: implicações sociais, econômicas e políticas do uso do computador na educação de países em desenvolvimento; integração do computador no processo de ensino-aprendizagem; e vantagens, limitações e viabilidade da integração do computador no contexto da educação brasileira. [RESENHA, 1983, p. 35-6]

\footnotetext{
${ }^{19}$ Diário Oficial da União, Seção I, 19/03/80, p. 4857; 24/03/80, p. 5202; 17/06/80, p. 12012 e 17/07/80, p. 14266.
} 
Pouco antes, o conjunto de prioridades e estratégias apresentadas no III Plano Setorial de Educação, Cultura e Desporto ${ }^{20}$, elaborado pelo MEC para orientar suas ações no período que se iniciava em 1980, traduziria a percepção dos atores que atuavam na educação, tanto nas universidades, como no governo, de que a questão da tecnologia estava ligada ao "aproveitamento das tecnologias modernas de comunicação, particularmente do rádio e da televisão, não apenas como forma de atualização mas, principalmente, como instrumento de democratização de oportunidades" [MEC, 1980, p. 48].

Em 1983, a Secretaria de Informática (SEINF) do MEC publicou uma coletânea de pequenos textos de autores brasileiros e de outras nacionalidades, intitulada 'Informática e Educação, com o objetivo de nivelar informações e estimular debates no tema Informática e Educação. Um dos textos, de autoria de Seymour Papert, publicado originalmente em 1980, explicava a relação entre a constituição um mercado para equipamentos de informática e o uso de computadores nas escolas:

\begin{abstract}
Será mais fácil compreender a minha idéia, comparando o mercado da educação com o mercado de outros produtos. Se você inventar um novo utensílio de cozinha e provar que existe mercado para um milhão de pessoas, facilmente encontrará o capital para desenvolver a idéia e colocá-la no mundo. Porém, se você inventar um novo método de aprendizagem da matemática, o fato de interessar a um milhão de pessoas pode não ser suficiente para obter um financiamento,... . Mas, se existirem alguns milhões de possuidores de computadores domésticos, esses indivíduos constituirão um mercado pronto a gastar dólares pessoais em benefício de suas crianças. Este fato encorajará pessoas criativas a introduzirem-se no campo da inovação educacional em números imprevisíveis. Isto se tornará parte da criação de uma nova classe de profissionais e de empresários, e, talvez mesmo, de "estrelas", de forma análoga ao que aconteceu ao longo do aparecimento do cinema como uma cultura. [MEC. SEINF, 1983, p. 45]
\end{abstract}

\title{
5. Conclusão
}

A apresentação da coletânea mencionada informa que no contexto do fortalecimento do conhecimento como elemento de sobrevivência, o uso do computador podia ser entendido como "pomo da discórdia", mas continuaria a ser disseminado "espontaneamente" e que caberia uma reflexão sobre "alternativas para implementação, a curto e médio prazos, de uma política de informática mais agressiva no setor educação". [MEC. SEINF, 1983, p. 5]. Grande parte dos textos nela publicados previa e discutia um conjunto de mudanças culturais e técnicas, descritas por alguns autores como 'incômodas', 'bem vindas' ou 'inexoráveis'.

Nesta mesma coletânea foi republicado artigo do jornal Data News, de 2 de novembro de 1982, que relatava a divulgação feita pela Secretaria Especial de Informática (SEI), durante o seminário "A Informática na Educação", realizado no Rio de Janeiro, de um projeto-piloto nacional, a ser desenvolvido conjuntamente pela SEI,

\footnotetext{
${ }^{20}$ Construído através de encontros regionais que participaram secretarias e conselhos de educação, universidades federais, delegacias e superintendências regionais do MEC e outros órgãos envolvidos em atividades de educação, cultura e desportos [MEC, 1979]
} 
ligada ao Conselho de Segurança Nacional da Presidência da República - CSN/PR, pelo Conselho Nacional de Desenvolvimento Científico e Tecnológico (CNPq), então subordinado à Secretaria de Planejamento da Presidência da República - SEPLAN/PR e FINEP, então vinculada ao Ministério do Planejamento ${ }^{21}$. Este projeto viria a ser o EDUCOM.

O então responsável pelo projeto na SEI, Feres Jaber, que participou do debate "Em direção de uma experiência-piloto brasileira de informática na educação", no qual o lançamento da proposta do EDUCOM ocorreu, deu à sua fala um tom de urgência, indicando que "o Brasil não pode mais pagar o preço da inércia".

Expressou também sua preocupação com a questão do desenvolvimento de software educacional nacional, pois o software estrangeiro conteria "ideologias embutidas", e articulou a proposta que estava sendo apresentada diretamente à questão da produção de equipamentos, ao afirmar que:

"[A] indústria de hardware brasileira tem condições de suportar esse projeto. Precisamos usar o computador como os nossos pais usaram a lousa e o carvão, que nos nossos dias já se transformaram em quadronegro e giz. Precisamos habilitar a sociedade do ano 2000, pois ela será constituída pelas crianças de hoje, que não podem ser cerceadas desse processo" [MEC. SEINF, 1983, p. 72, grifos nossos]

A partir dos elementos apresentados, é possível perceber naquele começo dos anos 1980 que existiam diferentes percepções sobre o papel da tecnologia na educação. Para a SEI, uma questão de formação de recursos humanos e, eventualmente, de mercado para o setor de informática, para o MEC, a preocupação com ampliação do acesso através da tele-educação. Esta diferença pode ser uma das explicações para que os primeiros movimentos de proposição da investigação do uso da informática na educação escolar não tivessem partido de mobilização do MEC, mas da SEI, e para que, como consequência, ao menos inicialmente, os professores de sala de aula não fossem incluídos nessa construção.

Podemos perceber desde as origens do processo de introdução da informática na educação, um fato que persiste até hoje, ou seja, os educadores e professores ficam quase à margem desses processos. Os projetos para o uso da tecnologia na educação envolvem técnicos e especialistas de áreas relacionadas com a tecnologia mas não envolvem os profissionais diretamente envolvidos com a educação os professores de sala de aula. [BONILLA, 2000]

Quanto ao EDUCOM sua importância no fortalecimento de grupos de pesquisa sobre o uso da tecnologia da informação na educação e no início da construção de estruturas de apoio técnico e metodológico, ampliada por programas posteriores, é reconhecida por vários autores. Por exemplo, para Oliveira (1997), os centros de pesquisa envolvidos no Educom tornaram-se referências nacionais no campo da informática educativa, tendo se transformado, pelo menos até o final da década de 1970, nos principais responsáveis pela produção de softwares educativos e pela formação de recursos humanos para atuação no tema no Brasil.

\footnotetext{
${ }^{21}$ CNPq e FINEP viriam a ser incorporados ao Ministério de Ciência e Tecnologia em 1985, a partir da criação daquele ministério (Decreto $\mathrm{n}^{\circ}$ 91.146, de 15 de março de 1985).
} 


\section{Referências}

ADLER, Emanuel. Ideological "Guerrillas" and the Quest for Technological Autonomy: Brazil's Domestic Computer Industry. International Organization, The MIT Press, v. 40, n. 3, Jul. 1986, p. 673-705. Disponível em:

<http://www.jstor.org/stable/2706823 >. Acesso em: 11 out. 2016.

ALMEIDA, Fernando José de. Educação e informática: os computadores na escola. São Paulo: Cortez Editora: Editora Autores Associados, 1988. 103 p. (Coleção Polêmicas do Nosso Tempo 19)

ALMEIDA, Maria Elizabeth Bianconcini de. O aprender e a informática: a arte do possivel na formação do professor. $\mathrm{PROINFO/SEED/MEC,} \mathrm{Coleção} \mathrm{Informática}$ para a mudança na Educação, 1999. 39 p.

$<$ http://www.dominiopublico.gov.br/pesquisa/DetalheObraForm.do?select_action=\& co_obra=40245 >. Acesso em: 15 mai. 2015.

BETING, Joelmir. Os computadores. Folha de São Paulo, Terceiro Caderno Economia, Coluna Notas Econômicas, 18 out. 1972, p. 21.

BOMENY, Helena. O sentido político da educação de Jango. A trajetória política de João Goulart. 2004. FGV/CPDOC. Disponível em:

$<$ https://cpdoc.fgv.br/producao/dossies/Jango/artigos/NaPresidenciaRepublica/O_sen tido_politico_da_educacao_de_Jango>. Acesso em: 17 fev. 2016.

BONILlA, Maria Helena Silveira; PRETTO, Nelson De Luca. Políticas brasileiras de educação e informática. 2000. 21 p. Disponível em:

<http://www2.ufba.br/ bonilla/politicas.htm>. Acesso em: 13 fev. 2014.

BRASIL. Lei $n^{\circ} 5.692$, de 11 de agosto de 1971. Fixa Diretrizes e Bases para o ensino de $1^{\circ}$ e $2^{\circ}$ graus, e dá outras providências. Diário Oficial da União, de 12 ago. 1971. Disponível em: <http://www.planalto.gov.br/CCIVIL_03/leis/L5692.htm>. Acesso em 17 ago. 2015.

BRASIL. Decreto $n^{\circ} 70.370$, de 5 de Abril de 1972. Cria a Comissão de Coordenação das Atividades de Processamento Eletrônico, e dá outras providências. Diário Oficial da União, Seção 1, 6 abr. 1972. Disponível em:

<http://www2.camara.leg.br/legin/fed/decret/1970-1979/decreto-70370-5-abril-1972418827-publicacaooriginal-1-pe.html>. Acesso em 17 ago. 2015.

BRASIL. Presidência da República. II Plano Nacional de Desenvolvimento - 19751979. Brasília, 1974. 149 p. Disponível em:

<http://bibspi.planejamento.gov.br/handle/iditem/492>. Acesso em: 28 out. 2016.

BRASIL. Decreto $n^{\circ} 77.118$, de 9 de fevereiro de 1976. Reestrutura a Comissão de Coordenação das Atividades de Processamento Eletrônico (CAPRE) e lhe dá novas atribuições. Diário Oficial da União - Seção 1, 10 fev. 1976, p. 1957. Disponível em: <http://www.camara.gov.br/legin/fed/decret/1970-1979/decreto-77118-9-fevereiro1976-425743-publicacaooriginal-1-pe.html>. Acesso em 17 ago. 2015.

BRASIL. Lei $n^{o} 7.463$, de 17 de abril de 1986. Dispõe sobre o I Plano Nacional de Informática e Automação. Disponível em: $<$ http://legis.senado.gov.br/legislacao/ListaTextoIntegral.action?id=107130>. Acesso em: 29 ago. 2016. 
CASTRO, Márcia Correa. Enunciar democracia e realizar o mercado: políticas de tecnologia na educação até o Proinfo integrado (1973-2007). 2011. 146 f.

Dissertação (Mestrado) - Pontifícia Universidade Católica do Rio de Janeiro, Departamento de Educação. Rio de Janeiro, 2011. Orientador: José Mauricio Paiva Andion Arruti. Disponível em: $<$ http://www.maxwell.vrac.pucrio.br/Busca_etds.php?strSecao=resultado\&nrSeq=18430@1>. Acesso em: 18 jul. 2016.

CHAVES, Eduardo Oscar de Campos et al. Projeto Educom: Proposta Original. Memos do NIED, v. 1, n. 1, 1983, 15 p. Disponível em: <http://www.nied.unicamp.br/ojs/index.php/memos/article/view/57>. Acesso em:25 fev. 2015.

CHAVES, Eduardo Oscar de Campos. O Uso de Computadores em Escolas: Fundamentos e Críticas. Disponível em: <http://www.ich.pucminas.br/pged/db/wq/wq1/local/ec_scipione.htm>. Acesso em: 28 out. 2016. [Este tex to é a contribuição de Eduardo O C Chaves ao livro O Uso de Computadores em Escolas, escrito por ele e por Valdemar W. Setzer (Editora Scipione, São Paulo, 1988), pp.5-67].

CONSELHO DE SEGURANÇA NACIONAL (CSN). Secretaria Especial de Informática (SEI). Termo aditivo ao convênio firmado entre a Secretaria de Planejamento da Presidência da República e a Financiadora de Estudos e Projetos Finep em 28 de junho de 1975. Diário Oficial da União, 14 fev. 1980, Seção I, Parte I, p. 2995. Disponível em: 〈http://www.jusbrasil.com.br/diarios/3132574/pg-59secao-1-diario-oficial-da-uniao-dou-de-14-02-1980/pdfView>. Acesso em: 28 out. 2016.

CUKIERMAN, Henrique Luiz; CASTRO, Rachel Gonçalves de; ALVES, Luiz Augusto da Silva. Os debates parlamentares das leis de informática (1984, 1991, 2001, 2004). Simpósio de História da Informática na América Latina e Caribe. II SHIALC, CLEI XXXVIII, Medellín/Colômbia, 1 a 5 de outubro de 2012. 11 p. Disponível em: <http://www.cos.ufrj.br/shialc/> ou $<$ http://www.cos.ufrj.br/shialc/content/docs/shialc_2/clei2012_submission_331.pdf $>$. Acesso em: 25 mar. 2015.

CUKIERMAN, Henrique Luiz. Ementa da disciplina Computadores como construções sociotécnicas. (HCTE e PESC/COPPE; UFRJ) 2013. 5 p. (memo)

CUKIERMAN, Henrique. A publicidade dos minicomputadores made in Brazil e a experiência da reserva de mercado dos anos 70/80. XL Conferencia Latinoamericana en Informática. SHIALC 2014, Montevideo, Uruguai, Set. 15-19 2014, p. 17-25. Disponível em: 〈http://clei.org/proceedings/proceedingsSHIALC2014.pdf>. Acesso em: 26 ago. 2016

DANTAS, Marcos. O crime de Prometeu: como o Brasil obteve a tecnologia da informática. Rio de Janeiro: ABICOMP, 1989. 75 p. Disponível em: <http://www.mci.org.br/biblioteca/o_crime_de_prometeu.pdf>. Acesso em: 7 nov. 2016.

DANTAS, Vera. A guerrilha tecnológica: a verdadeira história da política nacional de informática. Rio de Janeiro: LTC-Livros Técnicos e Científicos Ed., 1988. 183 p. 
Disponível em: 〈http://www.mci.org.br/biblioteca/guerrilha_tecnologica.pdf $>$. Acesso em: 27 mar. 2014.

DIÁRIO Oficial da União (DOU), Brasília, DF, 9 maio 1975, Seção 1, Parte 1, p. 559092. Disponível em: <http://www.jusbrasil.com.br/diarios/3087698/pg-39-secao-1diario-oficial-da-uniao-dou-de-09-05-1975/pdfView>. Acesso em: 1 jul. 2016

DIAS, Rafael de Brito. Sessenta anos de política científica e tecnológica no Brasil. Campinas, SP: Ed. Unicamp, 2012. 256p.

FAJNZYLBER, Pablo. A indústria de informática no Brasil: capacitação tecnológica e suporte governamental. Revista do BNDES, Rio de Janeiro, v. 1, n. 2, p. 251-8, dez.1994. Disponível em:

<http://www.bndes.gov.br/SiteBNDES/export/sites/default/bndes_pt/Galerias/Arquiv os/conhecimento/revista/rev213.pdf>. Acesso em 3 set. 2016.

GARCIA, Renato; ROSELINO, José Eduardo. Uma avaliação da lei de informática e de seus resultados como instrumento indutor de desenvolvimento tecnológico e industrial. Gestão \& Produção, v.11, n.2, p.177-185, mai.-ago. 2004. Disponível em: <http://www.scielo.br/pdf/gp/v11n2/a04v11n2>. Acesso em: 22 jun. 2016.

GHIRALDELLI JR., Paulo. Introdução à Educação Escolar Brasileira: História, Política e Filosofia da Educação [versão prévia] 2001. 241 p. Disponível em: <http://www.miniweb.com.br/educadores/artigos/pdf/introdu-edu-bra.pdf $>$. Acesso em: 4 jan. 2016.

GUTIERREZ, Regina Maria Vinhais. Complexo eletrônico: Lei de Informática e competitividade. BNDES Setorial, n. 31, Eletrônico, mar. 2010, p. 5-48. Disponível em:

<http://www.bndes.gov.br/SiteBNDES/export/sites/default/bndes_pt/Galerias/Arquiv os/conhecimento/bnset/set3101.pdf >. Acesso em: 4 jul. 2016.

HELENA, Silvia. A indústria de computadores: evolução das decisões governamentais. Revista de Administração Pública, Rio de Janeiro, v. 14, n. 4, p. 73-109, out./dez. 1980. Disponível em: <http://bibliotecadigital.fgv.br/ojs/index.php/rap/article/viewFile/7592/6106>. Acesso em: 30 set. 2016.

HELENA, Silvia. Rastro de Cobra. [s.1.], 1984, 74 p. Disponível em: <http://www.mci.org.br/biblioteca/rastro_de_cobra.pdf>. Acesso em: 7 nov. 2016.

HEYMANN, Luciana Quillet. Desafios e rumos da política educacional. A trajetória política de João Goulart. 2004. FGV/CPDOC. Disponível em: <https://cpdoc.fgv.br/producao/dossies/Jango/artigos/NaPresidenciaRepublica/Desafi os_e_rumos_da_politica_educacional>. Acesso em: 17 fev. 2016.

LUCENA, Carlos J.; MARTINS, Luiz. A multilevel national approach to computer education. P. 145-150. In: LECARME, Olivier; LEWIS, Robert (Eds.). Computers in education: proceedings of the IFIP $2 d$ World Conference, International Federation for Information Processing, Association française pour la cybernétique économique et technique. Amsterdam: North-Holland Publishing Company, 1975.1020 p. Disponível em: <ftp://ftp.inf.pucrio.br/pub/docs/Publications/75_PI_Lucena_IFIP.pdf>. Acesso em: 15 nov. 2015. 
MACEDO, Paulo Brígido Rocha. Escolaridade, experiência salários: uma análise do setor de processamento eletrônico de dados no Brasil. Dissertação (Mestrado em Economia), Fundação Getúlio Vargas. Escola de Pós-Graduação em Economia (EPGE). Instituto Brasileiro de Economia. Rio de Janeiro, RJ, Dezembro, 1982. 198 p. Disponível em: 〈http://bibliotecadigital.fgv.br/dspace/handle/10438/95>. Acesso em: 19 jul. 2016.

MARQUES, Ivan da Costa. Computadores: parte de um caso amplo da sobrevivência e da soberania nacional. Revista de Administração Pública, Rio de Janeiro, v. 14, n. 4, p. 110-147, out./dez. 1980. Disponível em: <http://bibliotecadigital.fgv.br/ojs/index.php/rap/article/viewFile/7593/6107>. Acesso em: 31 jan. 2015.

MARQUES, Ivan da Costa. Reserva de mercado: um mal entendido caso políticotecnológico de "sucesso" democrático e "fracasso" autoritário. Revista de Economia, Curitiba, Editora da UFPR, n. 24, p. 89-114, 2000. Disponível em: $<$ http://revistas.ufpr.br/economia/article/viewFile/1984/1645>. Acesso em: 25 jul. 2016.

MARQUES, Ivan da Costa. Minicomputadores brasileiros nos anos 1970: uma reserva de mercado democrática em meio ao autoritarismo. História, Ciências, SaúdeManguinhos, Rio de Janeiro, v. 10, n. 2, p. 657-681, mai-ago. 2003 . Disponível em: $<$ http://www.scielo.br/scielo.php?script=sci_arttext\&pid=S010459702003000200008\&lng=en\&nrm=iso>. Acesso em: 27 Jul. 2016.

MARQUES, Ivan da Costa. Depoimento e pesquisa: três empresários protagonistas da reserva de mercado dos computadores no Brasil. Simpósio de História da Informática na América Latina e Caribe. I SHIALC. CLEI XXXVI, Assunção, Paraguai, outubro de 2010. 12 p. Disponível em: <http://www.cos.ufrj.br/shialc/content/docs/3.6_19SHIALCMarques_paper.pdf $>$. Acesso em 13 set. 2015

MARQUES, Ivan da Costa. O Brasil e seus ridículos tiranos: 1979/1980 tecnologia de minicomputadores e a História do Índio. Simpósio de História da Informática na América Latina e Caribe. II SHIALC, CLEI XXXVIII, Medellín/Colômbia, 1 a 5 de outubro de 2012. 11 p. Disponível em: $\langle$ http://www.cos.ufrj.br/shialc/content/docs/shialc_2/clei2012_submission_269.pdf $>$. Acesso em: 13 fev. 2016.

MARQUES, Ivan da Costa. Revisitando o discurso mobilizador da "reserva de mercado" dos anos 1970 à luz dos Estudos CTS. XL Conferencia Latinoamericana en Informática. III SHIALC 2014, Montevideo, Uruguai, Set. 15-19 2014, p. 41-47. Disponível em: <http://clei.org/proceedings/proceedingsSHIALC2014.pdf>. Acesso em: 26 ago. 2016

MEC. Secretaria Geral. A Política e o Plano Setorial de Educação e Cultura. Brasília, ago. 1973. 39 p. Disponível em: <http://www.dominiopublico.gov.br/download/texto/me001755.pdf $>$. Acesso em: 28 out. 2016.

MEC. Secretaria Geral. III Plano Setorial de Educação, Cultura e Desporto; 1980/1985. Brasília, MEC/DDD, 1980. 50 p. Disponível em: 
$<$ http://www.dominiopublico.gov.br/pesquisa/DetalheObraForm.do?select_action=\& co_obra $=26668>$. Acesso em: 28 de out. de 2016.

MEC. Secretaria de Informática (SEINF). Informática e Educação, Brasília, DF, 1983. 84 p. Disponível em: <http://dominiopublico.mec.gov.br/download/texto/me002721.pdf> . Acesso em: 31 jan. 2015.

MENEZES, Ebenezer Takuno de; SANTOS, Thais Helena dos. "Projeto Saci" (verbete). Dicionário Interativo da Educação Brasileira - EducaBrasil. São Paulo: Midiamix Editora, 2002. Disponível em: 〈http://www.educabrasil.com.br $\rangle$. Acesso em: 31 ago. 2015.

MINTO, Lalo Watanabe. Verbete 'Teoria do Capital Humano' e Verbete 'MECUSAID'. Glossário do projeto 'Navegando na História da Educação Brasileira'. Grupo de Estudos e Pesquisas "História, Sociedade e Educação no Brasil" (HISTEDBR). Faculdade de Educação, UNICAMP. [2006?]. Disponível em: $<$ http://www.histedbr.fe.unicamp.br/navegando/glossario/verb_c teoria_\%20do_capi tal_humano.htm> e <http://www.histedbr.fe.unicamp.br/navegando/glossario/verb_c_mecusaid\%20.htm >. Acesso em: 10 jul. 2015.

MIRA, Marilia Marques; ROMANOWSKI, Joana Paulin. Tecnicismo, neotecnicismo e as práticas pedagógicas no cotidiano escolar. Anais do IX Congresso Nacional de Educação - EDUCERE e III Encontro Sul Brasileiro de Psicopedagogia, Pontifícia Universidade Católica do Paraná (PUCPR), Curitiba, 26 a 29 out. 2009, p. 1020810219. Disponível em: <http://www.marcelo.sabbatini.com/wpcontent/uploads/downloads/neotecnicismo.pdf>. Acesso em: 11 fev. 2016.

MORAES, Raquel de Almeida. A Política de Informática na Educação Brasileira: do Nacionalismo ao Neoliberalismo. Campinas, 1996, 218p. Tese (Doutorado). Faculdade de Educação, Unicamp, 1996. Disponível em: $<$ http://www.bibliotecadigital.unicamp.br/document/?code $=\mathrm{vtls} 000114823 \& \mathrm{fd}=\mathrm{y}>$. Acesso em: 13 ago. 2015.

MOREIRA, José de Albuquerque. Informática: o mito Política Nacional de Informática. Revista de Biblioteconomia de Brasília, v. 19, n. 1, p. 23-50, jan.-jun. 1995. Disponível em: <http://www.brapci.ufpr.br/brapci/_repositorio/2010/03/pdf_d6a0b6ef05_0008922.p df >. Acesso em: 17 ago. 2015.

O SISTEMÁTICO. Publicação semanal do Centro de Computação da UFMG, Ano I, $\mathrm{n}^{\circ}$ 2, 23 jun. 1977). Disponível em: <https://www.cecom.ufmg.br/Sistantigos/si_ed_30anos_pag4.shtml > . Acesso em: 19 ago. 2016.

OLIVEIRA, João Batista Araújo e. Tecnologia educacional no Brasil. Cadernos de Pesquisa, São Paulo, n. 33, p. 61-69, maio 1980. Disponível em: <http://educa.fcc.org.br/pdf/cp/n33/n33a04.pdf>. Acesso em: 14 jan. 2016.

OLIVEIRA, Maria Rita Neto Sales. Educação e Informática. In: ANPEd (Associação Nacional de Pos-Graduação e Pesquisa em Educação). Avaliação e perspectivas na área de educação - 1982-91. Porto Alegre: ANPEd, set. 1993. 227 p. p. 91-110. 
[Relatório de pesquisa realizado por demanda e com financiamento do $\mathrm{CNPq}-$ Conselho Nacional de Desenvolvimento Científico e Tecnológico].

OLIVEIRA, Ramon de. Informática educativa: dos planos e discursos à sala de aula. Campinas: Papirus, 1997. 176 p.

PELEGRINI, Thiago; AZEVEDO, Mário Luiz Neves de. A Educação nos anos de chumbo: a Política Educacional ambicionada pela "Utopia Autoritária" (1964-1975). História e-História, Unicamp, 28 set. 2006. Disponível em: <http://www.historiahistoria.com.br/materia.cfm?tb=artigos\&id=46>. Acesso em: 23 jan. 2016.

RESENHA II. Seminário Nacional de Informática na Educação 1 e 2., Brasília e Salvador, 1981 e 1982. Anais, Brasília, SEI, 1982. 1 v. Em aberto (INEP), Brasília, ano 2, n. 17, jul. 1983. p. 35-38. Disponível em: <http://www.rbep.inep.gov.br/index.php/emaberto/article/view/1477/1452>. Acesso em: 7 mar. 2014.

SALLES FILHO, S. L. M. Política de Ciência e Tecnologia no I PND (1972/74) e no I PBDCT (1973/74). Revista Brasileira de Inovação, Campinas, v. 1, n. 2 jul./dez. 2002, p. 397-419. Disponível em: <http://ocs.ige.unicamp.br/ojs/rbi/article/view/249/163 > . Acesso em: 24 mar. 2016.

SALLES FILHO, S. L. M. Política de Ciência e Tecnologia no II PBDCT (1976).Política de Ciência e Tecnologia no II PBDCT (1976). Revista Brasileira de Inovação, Campinas, v. 2, n. 1 jan./jun.2003(a), p. 179-211. Disponível em: <http://ocs.ige.unicamp.br/ojs/rbi/article/view/256/172>. Acesso em: 24 mar. 2016.

SALLES FILHO, S. L. M. Política científica e tecnológica no III PBDCT (1980-85). Revista Brasileira de Inovação, Campinas, v. 2, n. 2, jul./dez. 2003(b). P. 407-432. Disponível em: 〈http://ocs.ige.unicamp.br/ojs/rbi/article/view/262/178>. Acesso em: 24 mar. 2016.

SALLES FILHO, Sergio et al. Avaliação de impactos da Lei de Informática: uma análise da política industrial e de incentivo à inovação no setor de TICs brasileiro. Revista Brasileira de Inovação, Campinas (SP), 11, n. esp., p. 191-218, julho 2012. Disponível em: 〈http://ocs.ige.unicamp.br/ojs/rbi/article/view/607/343 >. Acesso em: 22 jun. 2016.

SARTI, Cláudia Silva Lima Oliveira. A Política Nacional de Informática na educação: tentativa de compreensão da expressão do Estado. Campinas, SP, 2002. Orientadora: Eloísa de Mattos Höfling. Dissertação (mestrado). Universidade Estadual de Campinas, Faculdade de Educação. 187 p. Disponível em: <http://www.bibliotecadigital.unicamp.br/document/?code=vtls000278416\&opt=4>. Acesso em: 29 jan. 2015.

SOARES, Gustavo Gindre Monteiro. A política dos artefatos na Lei de Informática: o caso SOX. Trabalho apresentado no NP10 - Núcleo de Pesquisa Economia Política e Políticas Públicas de Comunicação, XXV Congresso Anual em Ciência da Comunicação, Salvador/BA, 04 e 05 set.2002. Disponível em: $<$ http://www.intercom.org.br/papers/nacionais/2002/congresso2002_anais/2002_NP1 OSOARES.pdf>. Acesso em: 27 jul. 2016. 
SOUZA, Heitor Gurgulino de. Informática na educação e ensino de informática: algumas questões. Em aberto, Brasília, ano 2, n. 17, jul. 1983, p. 1-8. Disponível em: <http://emaberto.inep.gov.br/index.php/emaberto/article/view/1472/1447>. Acesso em: 30 set. 2015.

STAA, Arndt von. Nossa história. Breve história do Departamento de Informática da PUC-Rio. 2003. Disponível em: 〈http://www.inf.puc-rio.br/?page_id=1691>. Acesso em: 18 out. 2015.

TAVARES, Neide Rodriguez Barea. História da informática educacional no Brasil observada a partir de três projetos públicos. 18 p. [2002?]. Disponível em: <http://www.lapeq.fe.usp.br/textos/tics/tepdf/neide.pdf >. Acesso em: 3 abr. 2014.

TERUYA, Teresa Kazuko; MORAES, Raquel de Almeida. Política de informática na educação e a formação de professores. 20 p. VIII Seminário Nacional de Estudos e Pesquisas "História, Sociedade e Educação no Brasil": História, Educação e Transformação: tendências e perspectivas, 30 jun. a 3 jul. 2009. Universidade Estadual de Campinas (UNICAMP). Disponível em: <http://www.histedbr.fe.unicamp.br/acer_histedbr/seminario/seminario8/_files/Ovwt rQCR.pdf $>$. Acesso em: 13 mar. 2014.

VALENTE, José Armando (Org.). O computador na sociedade do conhecimento. Campinas, SP:UNICAMP/NIED, 1999. 156 p. Capítulo 1. Informática na educação no Brasil: análise e contextualização histórica. José Armando Valente Disponível em: 〈http://www.nied.unicamp.br/oea/pub/livro1/>. Acesso em: 4 abr. 2014.

VIANNA, Marcelo. Processando o "surto de desenvolvimento" - Grupos técnicos estatais em busca de um CPD nos primórdios da Informática brasileira (1959-1961). XL Conferencia Latinoamericana en Informática. SHIALC 2014, Montevideo, Uruguai, 15-19 set. 2014, p. 100-111. Disponível em: <http://clei.org/proceedings/proceedingsSHIALC2014.pdf>. Acesso em: 26 ago. 2016.

VIANNA, Marcelo. "Está aí, e o de vocês?" - Dimensões da expertise, articulações políticas e outros recursos sociais na trajetória de um fabricante de computadores durante o regime militar. p. 1235 - 1269. In: VIANNA, Marcelo et al (Orgs.). O historiador e as novas tecnologias: reunião de artigos do II Encontro de Pesquisas Históricas - PUCRS [recurso eletrônico], Porto Alegre: Memorial do Ministério Público do Rio Grande do Sul, 2015(a). 2056 p.

VIANNA, Marcelo. Segurança Nacional e Autonomia Tecnológica - o avanço do Serviço Nacional de Informações sobre o campo da Informática brasileira (19781980). XXVIII Simpósio Nacional de História, 27-31 jul. 2015 (b), Florianópolis, 16 p. Disponível em: <http://www.snh2015.anpuh.org/resources/anais/39/1439738614_ARQUIVO_MAR CELOVIANNA_GT39-TRABALHOCOMPLETO.pdf>. Acesso em: 18 out. 2015.

VIEIRA, Sofia Lerche. A educação nas constituições brasileiras: texto e contexto. Revista Brasileira de Estudos Pedagógicos, Brasília, v. 88, n. 219, p. 291-309, maio/ago. 2007. Disponível em: <http://rbep.inep.gov.br/index.php/rbep/article/view/749 > . Acesso em 28 jan. 2016. 